\title{
Sorption of Chromium Ions from Aqueous Solution onto Chemically Activated Carbons Developed from Maize Cobs
}

\author{
A. M. Youssef ${ }^{1, \wedge}$, Th. El-Nabarawy ${ }^{2}$, Mona A. Shouman ${ }^{2}$ and S. A. Khedr ${ }^{2}$ \\ ${ }^{1}$ Faculty of Science, Mansoura University, Mansoura, Egypt \\ ${ }^{2}$ Physical Chemistry Department, National Research Centre, Dokki, Cairo, Egypt \\ ^e-mail: amyoussef2010@yahoo.com \\ (Received July 14, 2008; Accepted September 30, 2008)
}

\begin{abstract}
Chemically activated carbons were prepared from maize cobs, using phosphoric acid of variable concentration. The textural parameters of the activated carbons were determined from the nitrogen adsorption isotherms measured at $77 \mathrm{~K}$. The chemistry of the carbon surface was determined by measuring the surface $\mathrm{pH}$, the $\mathrm{pH}_{\mathrm{PZC}}$ and the concentration of the carbon - oxygen groups of the acid type on the carbon surface. Kinetics of $\mathrm{Cr}(\mathrm{VI})$ sorption/reduction was investigated at $303 \mathrm{~K}$. Two processes were investigated in terms of kinetics and equilibrium namely; $\mathrm{Cr}(\mathrm{VI})$ removal and chromium sorption were studied at various initial $\mathrm{pH}$ (1-7). Removal of $\mathrm{Cr}(\mathrm{VI})$ shows a maximum at $\mathrm{pH}$ 2.5. At $\mathrm{pH}<2.5$, sorption decreases because of the proton competition with evolved $\mathrm{Cr}(\mathrm{III})$ for ion exchange sites. The decrease of sorption at $\mathrm{pH}>2.5$ is due to proton insufficiency and to the decrease of the extent of $\mathrm{Cr}(\mathrm{VI})$ reduction. The chemistry of the surface of activated carbon is an important factor in determining its adsorption capacity from aqueous solutions particularly when the sorption process involves ion exchange.
\end{abstract}

Keywords : Textural parameter, Kinetics, Equilibrium, Adsorption, Chromium, Active carbon, Maize cobs

\section{Introduction}

The removal of toxic metal ions from aqueous solutions received a great deal of attention in the last years. Recently, Stringent statutory regulations have been introduced to reduce the discharge of toxic metals to low levels. The main sources of heavy metal pollution include: mining, petroleum, textile, milling and surface finishing industries which discharge a variety of toxic metals into the environment [1]. Treatments such as chemical precipitation membrane filtration, ion exchange, carbon sorption and coprecipitation adsorption have been suggested for the removal of heavy metals from wastewater [2]. Among these methods, carbon sorption is the most reactive because of its simplicity and economical feasibility $[3,4]$.

Hexavalent chromium is a toxic metal present in industrial waste water from various sources such as electroplating, leather tanning and mining industries, cement, steel and fertilizer manufacture, textile dyeing, wood preservative manufacture and photographic industries [5]. Such hexavalent chromium is primarily present in the form of $\mathrm{CrO}_{4}{ }^{2-}$ ions. It leads to liver damage, pulmonary congestion and Edema, and causes skin irritation in ulcer formation. The tolerance limit of $\mathrm{Cr}(\mathrm{VI})$ for discharge into inland surface water is $0.1 \mathrm{mg} / \mathrm{l}$ and in potable water is $0.05 \mathrm{mg} / 1$ [6].

The removal of $\mathrm{Cr}(\mathrm{VI})$ ions by activated carbon adsorption provides an effective and good alternative method [7].
Several recent publications have been devoted to prepare activated carbons from different inexpensive and abundantly available precursors such as leaf mould, coconut shells, saw dust, rice husk, used tyre carbon, cane bagasse, olive stones, cotton stalks and others.

Maize cobs are a cheap and abundant agricultural waste of no economic value. However, maize cobs-activated carbons have shown to be a highly porous and rich in microporosity and exhibiting high sorption capacity for methylene blue and $\mathrm{Pb}^{2+}$ [8]. Also chemically-activated carbons with an essential microporous structure could be obtained using zinc chloride or phosphoric acid as activating agents [9].

Adsorption of $\mathrm{Cr}(\mathrm{VI})$ on activated carbons and other sorbents has been the subject of several investigations $[10,11,12,13]$. However, the reported results are variable, particularly, in terms of optimum $\mathrm{pH}$ of chromium removal. Reduction of $\mathrm{Cr}$ (VI) to $\mathrm{Cr}$ (III) was observed with different sorbents $[14,15]$.Taking this in mind, more studies are still required towards improving knowledge already available.

In the present investigation, two processes were studied: $\mathrm{Cr}(\mathrm{VI})$ removal and chromium sorption. $\mathrm{Cr}(\mathrm{VI})$ removal from aqueous solution occurs via reduction to $\mathrm{Cr}$ (III) and adsorption of $\mathrm{Cr}(\mathrm{VI})$ on the sorbent surface. The process is followed by analyzing $\mathrm{Cr}(\mathrm{VI})$ concentration in the aqueous solution. However, chromium sorption refers to the uptake of total chromium, $\mathrm{Cr}(\mathrm{VI})$ and evolved $\mathrm{Cr}(\mathrm{III})$ from the aqueous solution by the sorbent and the process is followed 
by analyzing total chromium in the aqueous solution. Both processes were investigated using initial $\mathrm{Cr}(\mathrm{VI})$ concentration, $180 \mathrm{mg} / \mathrm{l}$, in the initial $\mathrm{pH}$ range 1.0-7.0. Different kinetic models were examined. The textural properties were determined from the nitrogen adsorption at $77 \mathrm{~K}$ and the chemistry of the surface of the investigated carbon was also investigated.

\section{Experimental}

\subsection{Sorbents}

Dried ground maize cobs were first thoroughly washed with water and then dried at $383 \mathrm{~K}$, after cooling to room temperature; they were soaked for $72 \mathrm{~h}$ in phosphoric acid solution of concentration 20,40 and $60 \mathrm{wt}$. \% with occasional shaking. The treated cobs were then filtered and dried to constant weight at $343 \mathrm{~K}$. The dried treated samples were then carbonized in absence of air at $723 \mathrm{~K}$. The carbonized products were then washed several times with distilled water until the $\mathrm{pH}$ of the resulting wash solution was c.a 6.0. Finally the carbonized products were crushed and then sieved with the particles within the range $100 \sim 200 \mu \mathrm{m}$ being used in the sorption measurements. In the designation of the carbons employed, $\mathrm{C}$ denotes maize cobs and $\mathrm{P}$ indicates treatment with phosphoric acid and the Arabic number following the letter $\mathrm{P}$ giving the $\mathrm{wt} \%$ of phosphoric acid employed. Thus, for example, CP40 stands for an activated carbon prepared by activation with $40 \mathrm{wt}$. \% phosphoric acid at $723 \mathrm{~K}$. All the chemicals used were of analytical grade.

\subsection{Characterization of the sorbents}

The textural properties (Specific Surface area and porosity) were determined from the adsorption of nitrogen at $77 \mathrm{~K}$ using conventional volumetric apparatus; the carbon sample was degassed at $473 \mathrm{~K}$ for $8 \mathrm{~h}$ under a reduced pressure of $10^{-5}$ Torr, prior to nitrogen adsorption. The chemistry of the carbon surface was investigated by measuring the surface $\mathrm{pH}$, the $\mathrm{pH}$ of the carbon at the point of zero charge $\mathrm{pH}_{\mathrm{PZC}}$ and the relative concentration of the surface functional groups of acidic type in the carbon [16]. The surface $\mathrm{pH}$ was measured following the ASTM method [17] $(1.0 \mathrm{~g}$ of the carbon sample was placed in $50 \mathrm{ml}$ stoppered glass bottle containing $20 \mathrm{ml} \mathrm{CO}$ - free distilled water. The bottles with their contents were shaken for $4 \mathrm{~h}$ and kept for $24 \mathrm{~h}$ at room temperature. The $\mathrm{pH}$ of the supernatant liquid was determined). Through the use of the mass-titration method [18], $\mathrm{pH}_{\mathrm{PZC}}$ were determined by placing various amounts of carbons in $50 \mathrm{ml}$ of $0.1 \mathrm{M} \mathrm{KNO}_{3}$ solution in $100 \mathrm{ml}$ bottles. The sealed bottles were then placed in a thermostat shaker overnight after which the

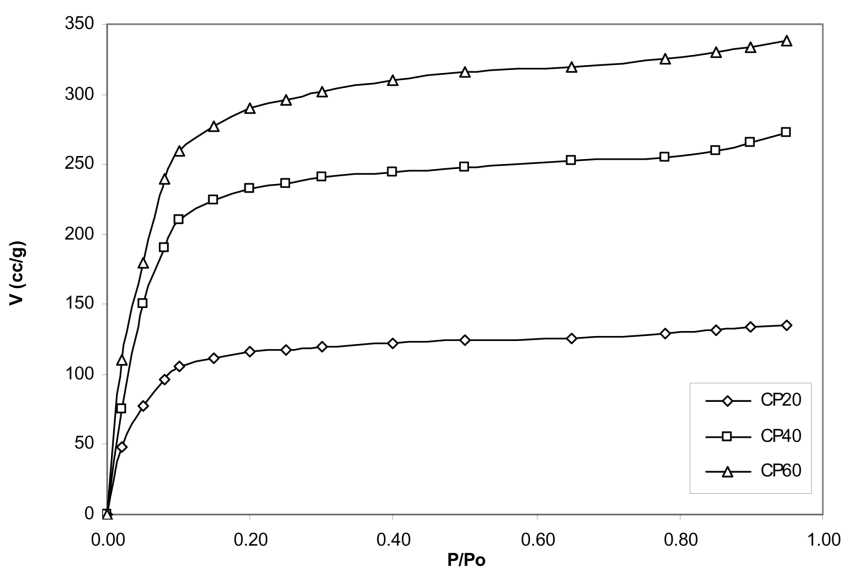

Fig. 1. Adsorption isotherms nitrogen at $-196^{\circ} \mathrm{C}$ onto $\mathrm{CP} 20$, CP40 and CP60.

equilibrium $\mathrm{pH}$ value of the mixture was measured. The limiting $\mathrm{pH}$ was taken as the value of $\mathrm{pH}_{\mathrm{PZC}}$.

The nitrogen adsorption isotherms (Fig. 1) are all type I according to Sing classification [20]. The specific surface areas $\mathrm{S}_{\mathrm{BET}}\left(\mathrm{m}^{2} / \mathrm{g}\right)$ were determined by applying the conventional BET equation [21] and the total pore volume $\mathrm{V}_{\mathrm{T}}(\mathrm{ml} / \mathrm{g})$ is read from the nitrogen uptake at $\mathrm{P} / \mathrm{P}_{\mathrm{o}}=0.95$. The micropore volume $\mathrm{V}_{\mathrm{m}}(\mathrm{ml} / \mathrm{g})$ is determined from the nitrogen uptake at $P / P_{o}=0.1$ and the mean pore radius $r_{m}$ $(\mathrm{nm})$ is calculated from the relationship

$$
r_{m}=\frac{2 V_{T} \cdot 10^{3}}{S_{B E T}}
$$

These textural parameters of the investigated carbons are listed in Table 1. Table 1 indicates that all the investigated carbons contain a large fraction of micropores and that the total pore volume and surface area increase with the increase of the concentration of phosphoric acid used. More details on the function of phosphoric acid and the activation process are reported elsewhere [22].

\subsection{Adsorption from solution}

A stock solution of $\mathrm{Cr}(\mathrm{VI}), 1000 \mathrm{mg} / \mathrm{l}$, was prepared in distilled water using $\mathrm{K}_{2} \mathrm{Cr}_{2} \mathrm{O}_{7}$ and all the working solutions were prepared by dilution in distilled water. Kinetic and batch experiments were undertaken by mixing $0.1 \mathrm{~g}$ carbon with $100 \mathrm{ml}$ of $\mathrm{Cr}(\mathrm{VI})$ solution $(180 \mathrm{mg} / \mathrm{l})$ at required initial $\mathrm{pH}(1.0-7.0)$ at $303 \mathrm{~K}$, in a shaking water bath $(200 \mathrm{rpm})$. The $\mathrm{pH}$ was adjusted by adding few drops of $0.1 \mathrm{M} \mathrm{H}_{2} \mathrm{SO}_{4}$ or $0.1 \mathrm{M} \mathrm{NaOH}$ prior to the addition of the sorbent.

$\mathrm{Cr}(\mathrm{VI})$ in solution was analyzed with Perkin - Elmer UVVis spectrophotometer model 550s using 1,5 diphenylcarbazide in acid medium [19]. Total chromium was determined using Perkin - Elmer atomic 2380 absorption spectrophotometer. The difference in concentration between the total chromium and $\mathrm{Cr}(\mathrm{VI})$ gives $\mathrm{Cr}(\mathrm{III})$ concentration. 
Table 1. Textural Properties of the Sorbents Investigated

\begin{tabular}{|c|c|c|c|c|c|}
\hline Sorbent & $\mathrm{S}_{\mathrm{BET}}\left(\mathrm{m}^{2} / \mathrm{g}\right)$ & $\mathrm{V}_{\mathrm{T}}(\mathrm{ml} / \mathrm{g})$ & $\mathrm{V}_{\mathrm{m}}(\mathrm{ml} / \mathrm{g})$ & $\mathrm{r}_{\mathrm{m}}(\mathrm{nm})$ & $\mathrm{V}_{\mathrm{m}} / \mathrm{V}_{\mathrm{T}}$ \\
\hline CP20 & 410.0 & 0.209 & 0.164 & 1.02 & 0.785 \\
\hline $\mathrm{CP} 40$ & 847.0 & 0.422 & 0.325 & 1.00 & 0.770 \\
\hline CP60 & 1016.0 & 0.524 & 0.403 & 1.03 & 0.769 \\
\hline
\end{tabular}

Table 2. $\mathrm{pH}_{\mathrm{PZC}}$, Surface $\mathrm{pH}$ of the Carbons Investigated and the Amount of Surface Acid Groups (meq/g)

\begin{tabular}{|c|c|c|c|c|c|c|c|}
\hline \multirow{2}{*}{ Sorbent } & \multirow{2}{*}{$\mathrm{pH}_{\mathrm{PZC}}$} & \multirow{2}{*}{ Surface $\mathrm{pH}$} & \multicolumn{5}{|c|}{ Surface acid functionality } \\
\hline & & & Carboxyl & lactonic & phenolic & carbonyl & Total \\
\hline CP20 & 2.9 & 4.2 & 0.54 & 0.37 & 0.48 & 0.30 & 1.69 \\
\hline CP40 & 2.6 & 3.7 & 1.45 & 0.52 & 1.28 & 0.46 & 3.71 \\
\hline CP60 & 2.2 & 4.0 & 2.35 & 0.63 & 2.05 & 0.64 & 5.71 \\
\hline
\end{tabular}

Experiments and analyses were carried out three times with the difference, in all cases not exceeding $2.5 \%$.

For the kinetic experiments at different periods of time, the $\mathrm{pH}$ of the reaction solution was measured and aliquot of supernatant was withdrawn for the analysis of $\mathrm{Cr}(\mathrm{VI})$ and total chromium. For the batch experiments, after the equilibrium time was reached, the final $\mathrm{pH}$ was recorded and aliquot of supernatant was withdrawn and analyzed for $\mathrm{Cr}(\mathrm{VI})$ and total chromium.

\section{Results and Discussion}

\subsection{The chemistry of the carbon surface}

The chemistry of the surface of an activated carbon is equally important to its textural parameters in determining its adsorption capacity. However, the chemistry of the carbon surface is more important than the textural parameters in case of adsorption from solution. Moreover, the role of the chemistry of the surface dominates the sorption from solution when the process involves cation exchange or charged species as in the case of metal ion sorption.

The chemistry of the carbon surface is mainly due to the existence at the surface of carbon-oxygen groups of acidic or basic type. However, for chemically - activated carbons, the density of the surface acidic groups is too high to mask the function of surface basic groups. The acidic carbon-oxygen groups include carboxylic, lactonic, phenolic and carbonyl groups. They are quantitatively determined by neutralization with basic groups of varying strength. Thus $\mathrm{NaHCO}_{3}$ neutralizes carboxylic groups whereas $\mathrm{Na}_{2} \mathrm{CO}_{3}$ determine both carboxylic and lactonic groups. $\mathrm{NaOH}$ as a strong base determine carboxylic, lactonic and phenolic groups. $\mathrm{NaOC}_{2} \mathrm{H}_{5}$ neutralizes carboxylic, lactonic, and phenolic groups, in addition to reaction with carbonyl group [23].

The surface $\mathrm{pH}$ is conventionally used as an indicator of the surface groups and $\mathrm{pH}_{\mathrm{PZC}}$ is another indicator of the surface functional groups on carbon sorbents. Table 2 lists the amount of surface acid groups (meq/g) together with the surface $\mathrm{pH}$ and $\mathrm{pH}_{\mathrm{PZC}}$ of the sorbents investigated. Table 2 reveals that: (i) the surface acidity as indicated by the decrease of both surface $\mathrm{pH}$ and $\mathrm{pH}_{\mathrm{PZC}}$ increased with the increase of the concentration of phosphoric acid used in carbon activation (ii) For all sorbents, carboxylic groups are more dominating, followed by phenolic groups and then come the lactonic groups. The concentration of the carbonyl groups are slightly lower than the concentration of lactones, this is true for all the sorbents. However, the reaction of carbonyl groups with $\mathrm{NaOC}_{2} \mathrm{H}_{5}$ is not a neutralization reaction since it does not involve exchange either by $\mathrm{H}^{+}$or $\mathrm{Na}^{+}$ions.

\subsection{Adsorption from solution}

\subsubsection{Equilibrium experiments}

Many investigations have been devoted to studying $\mathrm{Cr}$ (VI) sorption and a general agreement has been reported that $\mathrm{Cr}(\mathrm{VI})$ sorption depends on the initial $\mathrm{pH}$ of the sorption solution but, no agreement has been reached on the optimum $\mathrm{pH}$ of $\mathrm{Cr}(\mathrm{VI})$ sorption. This may be ascribed to variations in sorption conditions such as sorbent type, chemistry of the

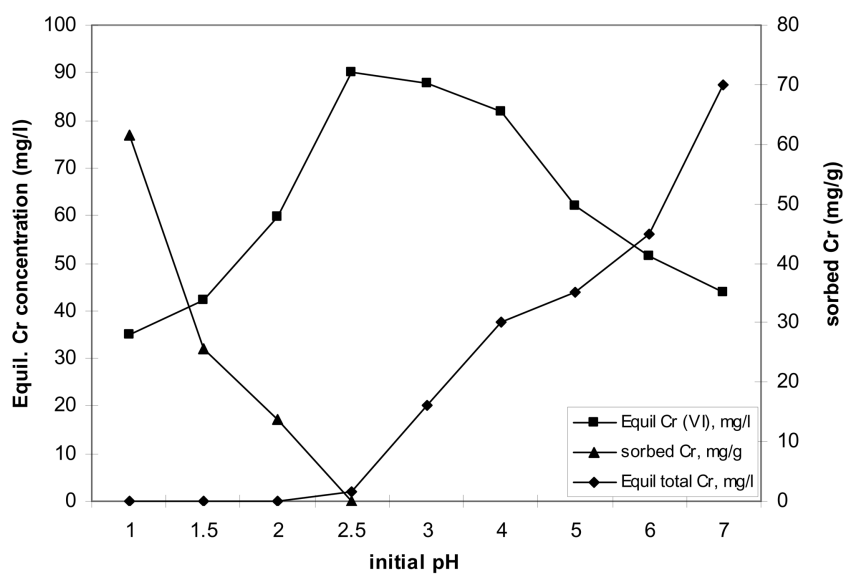

Fig. 2. Equilibrium $\mathrm{Cr}$ concentrations, equilibrium total $\mathrm{Cr}$ and sorbed $\mathrm{Cr}$ at different initial $\mathrm{pH}$ values at $30^{\circ} \mathrm{C}$. (initial $\mathrm{Cr}(\mathrm{VI})$ concentration $180 \mathrm{mg} / \mathrm{l})$. 
Table 3. Initial $\mathrm{pH}$, Final $\mathrm{pH}$ and Amount of Chromium Sorbed (mg/g) Onto CP60

\begin{tabular}{crrrrrrrrr}
\hline Initial $\mathrm{pH}$ & 1.0 & 1.5 & 2.0 & 2.5 & 3.0 & 4.0 & 5.0 & 6.0 & 7.0 \\
\hline Final $\mathrm{pH}$ & 1.1 & 1.7 & 2.3 & 4.3 & 5.0 & 6.1 & 6.5 & 6.9 & 7.6 \\
\hline Cr sorbed & 35.0 & 42.2 & 59.8 & 90.1 & 87.9 & 81.8 & 61.9 & 51.5 & 44.0 \\
\hline $\mathrm{pH}$ final & \multirow{2}{*}{1.1} & 1.1 & 1.2 & 1.7 & \multirow{2}{*}{1.7} & \multirow{2}{*}{1.5} & \multirow{2}{*}{1.3} & 1.2 & 1.1 \\
\hline $\mathrm{pH}$ initial & & & & & & & & \\
\hline
\end{tabular}

sorbent surface, the concentration of sorption solution and / or possibly other factors. In the present investigation, the equilibrium sorption by CP60 was undertaken using $180 \mathrm{mg} / \mathrm{l}$ (initial $\mathrm{Cr}(\mathrm{VI})$ concentration). A sorption maximum of 90.1 $\mathrm{mg} / \mathrm{g}$ was determined at $303 \mathrm{~K}$ and $\mathrm{pH} 2.5$ (Fig. 2). At initial $\mathrm{pH}<2.5$, Cr(VI) was hardly detected and $\mathrm{Cr}$ (III) was the main constituent of total chromium. A slight rise of the final $\mathrm{pH}$ was observed with low chromium sorption, (Table 3.) The final $\mathrm{pH}$ was low enough that protons compete with evolved $\mathrm{Cr}$ (III) ions for sorption at ion exchange sites such as $-\mathrm{COOH}$ and $-\mathrm{OH}$. Table 3 reveals also that at initial $\mathrm{pH}$ 2.5 , total chromium at equilibrium was minimal constituent $\mathrm{Cr}$ (VI) mostly with little or no Cr (III). This was associated with a considerable increase in the final $\mathrm{pH}$ and with the highest ratio of $\mathrm{pH}_{\text {final }} / \mathrm{pH}_{\text {initial }}$. These circumstances allowed most of evolved $\mathrm{Cr}$ (III) to be sorbed via ion-exchange and complexation. Within the initial $\mathrm{pH} 3.0-7.0$, the sorption capacity decreased with the increase of the initial $\mathrm{pH}$. However, no $\mathrm{Cr}$ (III) was detected in solution. Applying such relatively high $\mathrm{pH}$ values, $\mathrm{Cr}$ (VI) reduction is expected to decrease due to proton deficiency and thus little $\mathrm{Cr}$ (III) ions are evolved in solution. Accordingly, low chromium sorption is achieved even with an expected extent of physico-chemical adsorption of $\mathrm{Cr}(\mathrm{VI})$ within this $\mathrm{pH}$ [24]. Table 3 reveals also that the ratio $\mathrm{pH}_{\text {final }} / \mathrm{pH}_{\text {initial }}$ is the highest value when the initial applied $\mathrm{pH}$ was 2.5. This is associated with maximum chromium sorption which is probably due to ion exchange with the surface groups having exchangeable protons such as carboxylic and phenolic groups.

\subsubsection{Kinetics of chromium removal}

Kinetics of chromium removal and chromium sorption at $303 \mathrm{~K}$ by $\mathrm{CP} 60$, in the initial $\mathrm{pH}$ range $1.0-7.0$ was relatively slow approaching equilibrium in $60-90 \mathrm{~h}$ (Fig. 3a, b). It is depicted that $\mathrm{Cr}(\mathrm{VI})$ concentration and total Chromium concentration decrease with time. However, in the initial $\mathrm{pH}$ range 1.0-2.5, the decrease in the concentration of $\mathrm{Cr}(\mathrm{VI})$ was faster. The difference between total chromium and $\mathrm{Cr}(\mathrm{VI})$ may account for unsorbed $\mathrm{Cr}(\mathrm{III})$ as a result of $\mathrm{Cr}(\mathrm{VI})$ reduction. Under such low $\mathrm{pH}, \mathrm{Cr}$ (VI) may sorb without being reduced to $\mathrm{Cr}(\mathrm{III})$. This may explain the higher rate of $\mathrm{Cr}(\mathrm{VI})$ removal compared with that of total $\mathrm{Cr}$ sorbed (Fig. 3a).

The data obtained from the kinetic experiments were analyzed using two kinetic models, namely pseudo first order model and pseudo second order model [25], equations
(1) and (2)

$$
\begin{aligned}
& \log \mathrm{C}_{\mathrm{t}}=\log \mathrm{C}_{\mathrm{o}}-\frac{K_{1} t}{2.303} \\
& \frac{1}{\mathrm{C}_{\mathrm{t}}}=\frac{1}{\mathrm{C}_{\mathrm{o}}}+K_{2} t
\end{aligned}
$$

where $\mathrm{C}_{\mathrm{o}}$ and $\mathrm{C}_{\mathrm{t}}$ are the concentrations of $\mathrm{Cr}(\mathrm{VI})$ at equilibrium and at time $\mathrm{t}$, respectively. $K_{1}\left(\mathrm{hr}^{-1}\right)$ is the pseudo first order rate constant and $K_{2}\left(1 \mathrm{mg}^{-1} \mathrm{hr}^{-1}\right)$, is the pseudo second order rate constant for $\mathrm{Cr}(\mathrm{VI})$ removal.

In the initial $\mathrm{pH}$ range $3.0-7.0$, there was no difference in concentration of $\mathrm{Cr}(\mathrm{VI})$ and total chromium, because $\mathrm{Cr}$ (III) was no more available in solution. $\mathrm{Cr}(\mathrm{VI})$ removal data were found to fit well pseudo first order model at initial $\mathrm{pH} 1.0$ 2.0, slightly less fitting at initial $\mathrm{pH} 2.5$ and no fitting at

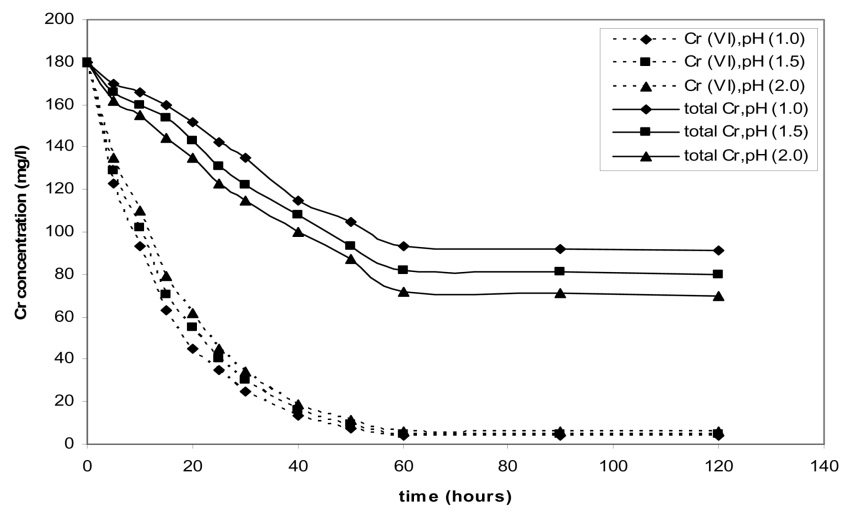

(a)

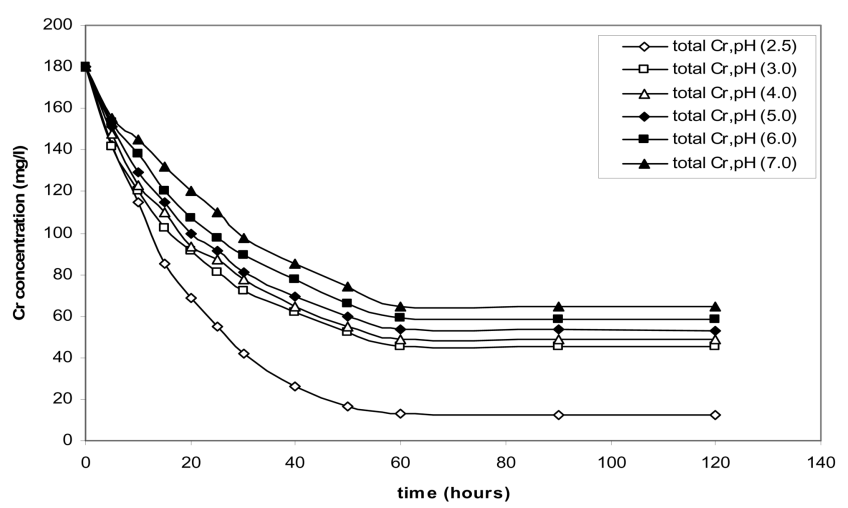

(b)

Fig. 3. Concentrations of $\mathrm{Cr}(\mathrm{VI})$ and total $\mathrm{Cr}$ versus time at different initial $\mathrm{pH}$ values. a) $\mathrm{pH} 1.0 \sim 2.0$ and b) $\mathrm{pH} 2.5 \sim 7.0$. 


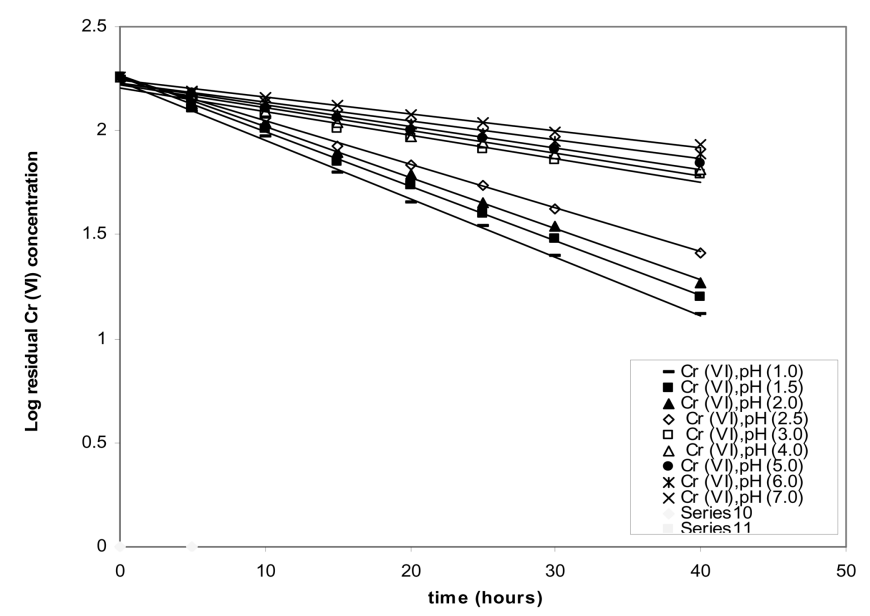

Fig. 4. Application of pseudo first order model for Cr (VI) removal at different initial $\mathrm{pH}$.

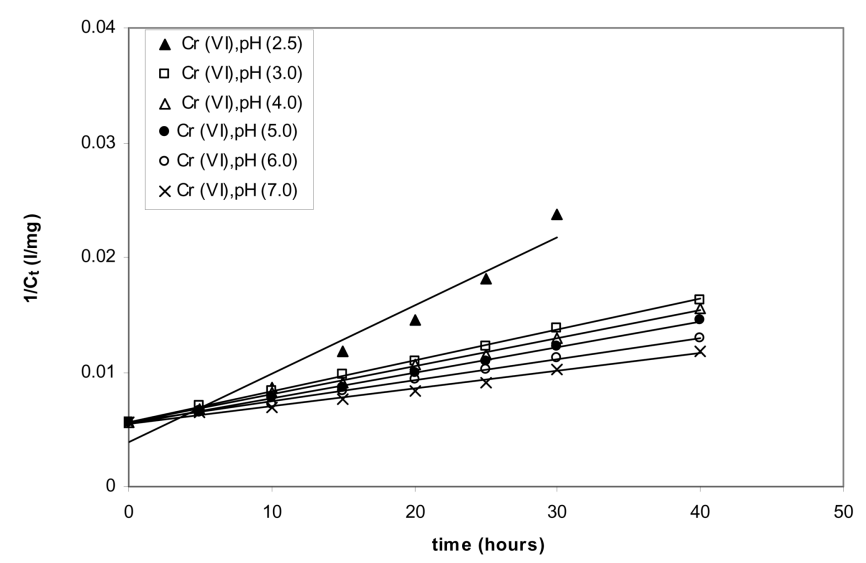

Fig. 5. Application of pseudo second order model for Cr (VI) removal at different initial $\mathrm{pH}$.

initial pH 3.0 - 7.0, Fig. 4 and Table 4.

Being a solid, the carbon concentration is considered as constant and therefore the order of $\mathrm{Cr}(\mathrm{VI})$ removal depend on the proton concentration $\left[\mathrm{H}^{+}\right]$and on $\mathrm{Cr}(\mathrm{VI})$ concentration $[\mathrm{Cr}(\mathrm{VI})]$. At initial $\mathrm{pH} 1.0,1.5$, and 2.0 the ratio $\left[\mathrm{H}^{+}\right]$ $/[\mathrm{Cr}(\mathrm{VI})]$ equals $28.9,9.13$, and 2.9 , respectively showing that $\left[\mathrm{H}^{+}\right]$is high enough to be considered as constant. Thus, at initial $\mathrm{pH}$ 1.0, 1.5 and 2.0, the removal of $\mathrm{Cr}(\mathrm{VI})$ follows pseudo first order kinetics. At initial $\mathrm{pH} 2.5$, the ratio $\left[\mathrm{H}^{+}\right] /$ [Cr (VI)] is 0.95 and this may explain the slight less fitting of the results of $\mathrm{Cr}(\mathrm{VI})$ removal at this particular $\mathrm{pH}$, to pseudo first order model. Further increase of the initial $\mathrm{pH}$ to 3.0-7.0 is associated with continuous decrease of the ratio $\left[\mathrm{H}^{+}\right] /[\mathrm{Cr}(\mathrm{VI})]$ showing thus the dependence of the reaction kinetics on both $\left[\mathrm{H}^{+}\right]$and $[\mathrm{Cr}(\mathrm{VI})]$, i.e. the reaction at this range of initial $\mathrm{pH}$ values would follow pseudo second order kinetics, Fig. 5 and Table 4.

\subsubsection{Kinetics of chromium sorption}

Table 4. Rate Constants of Cr (VI) Removal at Different Initial $\mathrm{pH}$ by $\mathrm{CP} 60$

\begin{tabular}{ccccc}
\hline Initial & \multicolumn{2}{c}{ Pseudo first order model } & \multicolumn{2}{c}{ Pseudo second order model } \\
$\mathrm{pH}$ & $K_{1}\left(\mathrm{~h}^{-1}\right)$ & $\mathrm{R}^{2}$ & $K_{2}(1 / \mathrm{mg} \mathrm{hr})$ & $\mathrm{R}^{2}$ \\
\hline 1.0 & 0.0647 & 0.9991 & $6.7 \times 10^{-4}$ & 0.865 \\
1.5 & 0.0621 & 0.9984 & $5.9 \times 10^{-4}$ & 0.890 \\
2.0 & 0.0595 & 0.9920 & $5.1 \times 10^{-4}$ & 0.898 \\
2.5 & 0.0430 & 0.9691 & $4.7 \times 10^{-4}$ & 0.973 \\
3.0 & 0.0267 & 0.9758 & $2.6 \times 10^{-4}$ & 0.999 \\
4.0 & 0.0244 & 0.9730 & $2.4 \times 10^{-4}$ & 0.998 \\
5.0 & 0.0230 & 0.9717 & $2.2 \times 10^{-4}$ & 0.999 \\
6.0 & 0.0219 & 0.9724 & $2.0 \times 10^{-4}$ & 0.999 \\
7.0 & 0.0198 & 0.9730 & $1.7 \times 10^{-4}$ & 0.994 \\
\hline
\end{tabular}

For chromium sorption based on the decrease in total $\mathrm{Cr}$ concentration with time, two kinetic models were considered, pseudo first order model and pseudo second order models, equations 3,4 , respectively [26,27]

$$
\begin{aligned}
& \log \left(\mathrm{q}_{\mathrm{e}}-\mathrm{q}_{\mathrm{t}}\right)=\log \mathrm{q}_{\mathrm{e}}-K_{1}^{\prime} \mathrm{t} / 2.303 \\
& \frac{t}{q_{t}}=\frac{1}{K_{2}^{\prime} q_{e}}+\frac{t}{q_{e}}
\end{aligned}
$$

where $\mathrm{q}_{\mathrm{e}}$ and $\mathrm{q}_{\mathrm{t}}$ are the amounts of chromium sorbed at equilibrium and at time $\mathrm{t}(\mathrm{mg} / \mathrm{g})$ respectively, $K_{1}^{\prime}\left(\mathrm{hr}^{-1}\right)$ and $K_{2}^{\prime}\left(\mathrm{g} \mathrm{mg}^{-1} \mathrm{hr}^{-1}\right)$ are the pseudo first order and pseudo second order rate constants: Here, the initial sorption rate $\mathrm{h}=$ $K_{2}^{\prime} \mathrm{q}_{\text {e }}^{2}(\mathrm{mg} / \mathrm{g} / \mathrm{h})$.

Fig. 6 shows that $\mathrm{pH} 2.5$ is the optimum for maximum chromium uptake. At $\mathrm{pH} 2.5, \mathrm{Cr}$ (III) develops in the early stage of sorption process and then slowly decreases almost to zero as equilibrium approaches. In the early stages, the protons released due to - $\mathrm{COOH}$ and - $\mathrm{OH}$ groups on the carbon surface. These protons compete with $\mathrm{Cr}$ (III) ions for ion exchange sites. As the reaction proceeds, more protons are consumed due to $\mathrm{Cr}(\mathrm{VI})$ reduction, and this allows evolved $\mathrm{Cr}$ (III) to be sorbed via ion exchange.

The isoelectric point (IEP) is an important parameter when charged species are sorbed from aqueous solution by carbonaceous sorbents [28]. IEP of the carbon sorbent CP60 was detected at $\mathrm{pH} 1.0$, while $\mathrm{pH}_{\mathrm{PZC}}$ was detected at $\mathrm{pH} 2.2$. A decrease in the $\mathrm{pH}$ below $\mathrm{pH}_{\mathrm{PZC}}$ means that both the surface of the sorbent and $\mathrm{Cr}$ (III) ions are positively charged and the uptake of metal ions is an exchange process of $\mathrm{Cr}$ (III) and protons [29]. However, the sorption maximum at $\mathrm{pH} 2.5$ is not only related to the value of $\mathrm{pH}_{\mathrm{PZC}}$ but mainly to the extent of $\mathrm{Cr}(\mathrm{VI})$ reduction and the rise of the final $\mathrm{pH}$ that allows the evolved $\mathrm{Cr}(\mathrm{III})$ to get sorbed via ion exchange.

Data of chromium sorption were found to fit well pseudo second order model (equation 4) in the whole $\mathrm{pH}$ range studied (Fig. 7). However, the data did not fit pseudo first order model (equation 3 ). $K_{2}^{\prime}$, h and the correlation coefficient $\mathrm{R}^{2}$ as determined by the application of equation 4 are 


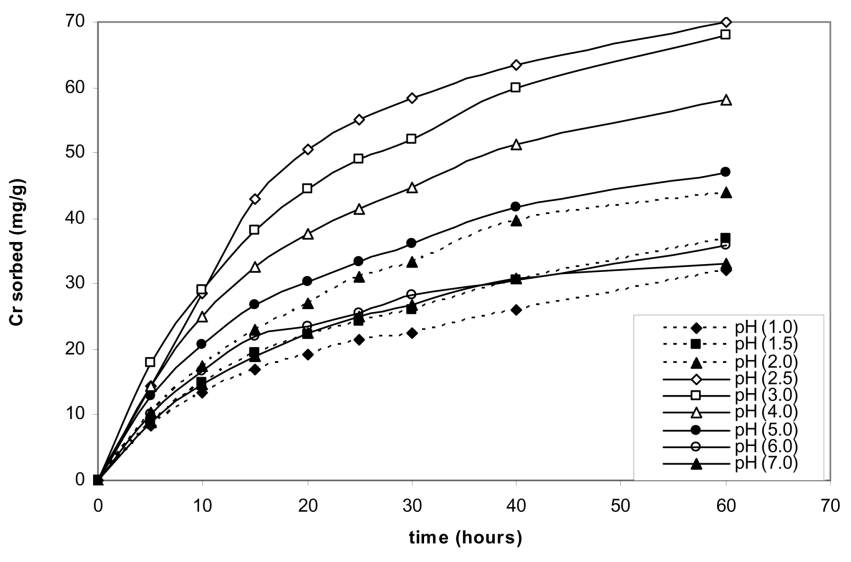

Fig. 6. Chromium sorption versus time at different initial $\mathrm{pH}$.

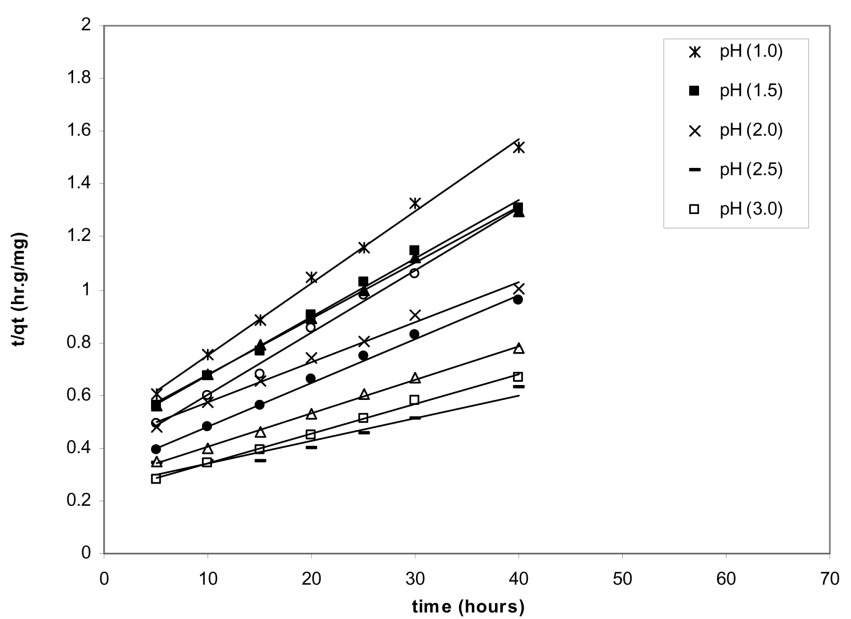

Fig. 7. Application of pseudo second order model for Cr sorption at different initial $\mathrm{pH}$.

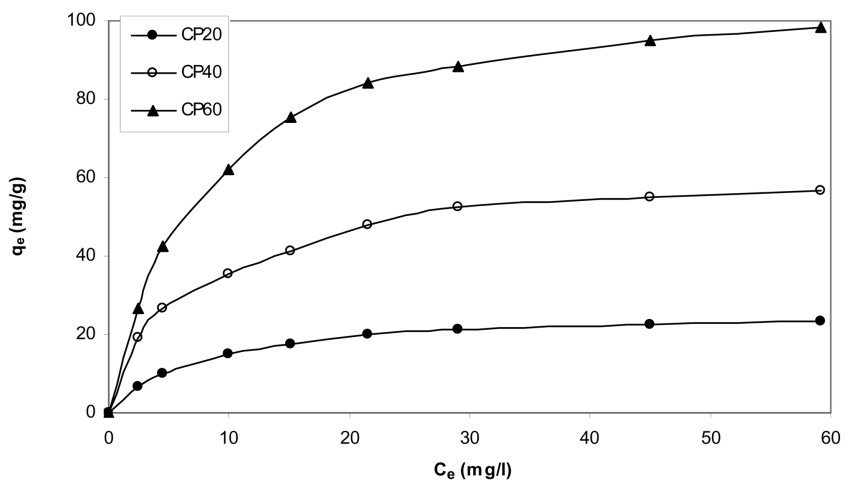

Fig. 8. Equilibruim adsorption isotherms of chromium at $30^{\circ} \mathrm{C}$ and $\mathrm{pH} 2.5$ onto CP20, CP40 and CP60.

listed in Table 5. This indicates that the sorption of total chromium complies very well with pseudo second order reaction and an activated sorption mechanism, and the rate depends both on the sorbent and sorbate concentration [26].
Table 5. Kinetic Parameters of Chromium Sorption at $30^{\circ} \mathrm{C}$ on CP60 at Different Initial pH Values

\begin{tabular}{ccccc}
\hline $\begin{array}{c}\text { Initial } \\
\mathrm{pH}\end{array}$ & $\begin{array}{c}\mathrm{q}_{\mathrm{e}} \\
(\mathrm{mg} / \mathrm{g})\end{array}$ & $\begin{array}{c}K_{2}^{\prime} \\
(\mathrm{g} / \mathrm{mg} \cdot \mathrm{h})\end{array}$ & $\begin{array}{c}\mathrm{h} \\
(\mathrm{mg} / \mathrm{g} \cdot \mathrm{h})\end{array}$ & $\mathrm{R}^{2}$ \\
\hline 1.0 & 35.0 & $18.6 \times 10^{-4}$ & 2.28 & 0.9959 \\
1.5 & 42.2 & $13.7 \times 10^{-4}$ & 2.44 & 0.9941 \\
2.0 & 44.0 & $12.9 \times 10^{-4}$ & 2.50 & 0.9917 \\
2.5 & 90.1 & $4.7 \times 10^{-4}$ & 3.85 & 0.9997 \\
3.0 & 87.9 & $5.2 \times 10^{-4}$ & 4.00 & 0.9970 \\
4.0 & 81.8 & $5.2 \times 10^{-4}$ & 3.45 & 0.9976 \\
5.0 & 61.9 & $8.2 \times 10^{-4}$ & 3.13 & 0.9941 \\
6.0 & 51.1 & $10.2 \times 10^{-4}$ & 2.71 & 0.9946 \\
7.0 & 44.0 & $11.5 \times 10^{-4}$ & 2.22 & 0.9979 \\
\hline
\end{tabular}

Table 5 depicts that the equilibrium sorption capacity increases with increase of the initial $\mathrm{pH}$ from 1.0 to 1.5 and further to 2.0 with the rise of the initial $\mathrm{pH}$ to 2.5 , the increase of the equilibrium sorption capacity was very high. Thus, with the rise of the initial $\mathrm{pH}$ from 2.0 to $2.5, \mathrm{q}_{\mathrm{e}}$ increased from 44.0 to 91.1 , i.e more than 2 fold increase. At initial $\mathrm{pH} 2.0, K_{2}^{\prime}$ was the minimum and $\mathrm{h}$ was the maximum. Further rise in the initial $\mathrm{pH}$ to 3.0 was associated with small decrease in $\mathrm{q}_{\mathrm{e}}$, this decrease continues upon further increase of the initial $\mathrm{pH}$.

It is now known that maximum chromium sorption at $30^{\circ} \mathrm{C}$ is obtained at initial $\mathrm{pH} 2.5$ and that the sorption process of chromium onto CP60 approaches equilibrium within $60 \sim 90 \mathrm{~h}$. This stimulated the study of chromium sorption at initial $\mathrm{pH} 2.5$ and at $303 \mathrm{~K}$ using different initial concentration of $\mathrm{Cr}(\mathrm{VI})$ and allowing the equilibrium to be attained. Such equilibrium sorption isotherms are undertaken not only for the sorbent CP60 but also for less phosphoric acid-activated carbons, CP20 and CP40. In each experiment a fixed amount of the sorbent $(0.1 \mathrm{~g})$ was contacted with $50 \mathrm{ml}$ of an aqueous solution of $\mathrm{Cr}(\mathrm{VI})$ of varying initial concentration $20 \sim 180 \mathrm{mg} / \mathrm{l}$. The initial $\mathrm{pH}$ was adjusted at 2.5 and the glass stoppered $100 \mathrm{ml}$ capacity bottles containing the resulting mixtures were left for $90 \mathrm{~h}$ with occasional shaking. After this time, the contents of the bottles were filtered and the equilibrium concentration $\mathrm{C}_{\mathrm{e}}$ $(\mathrm{mg} / \mathrm{l})$ of total chromium was determined and the chromium uptake $\mathrm{q}_{\mathrm{e}}(\mathrm{mg} / \mathrm{g})$ was calculated.

Fig. 8 shows the equilibrium sorption isotherms of chromium onto CP20, CP40 and CP60, at $303 \mathrm{~K}$ and with initial $\mathrm{pH}$ 2.5. The isotherms are of L-type according to Gile's classification [30]. The Langmuir equation [31] was used to analyze the chromium sorption data. Equation 5 is the linear form of Langmuir equation:

$$
\frac{C_{e}}{q_{e}}=\frac{1}{b q_{m}}+\frac{C_{e}}{q_{m}}
$$

$\mathrm{C}_{\mathrm{e}}$ and $\mathrm{q}_{\mathrm{e}}$ have been previously defined, $\mathrm{q}_{\mathrm{m}}$ is the maximum sorption capacity $(\mathrm{mg} / \mathrm{g})$ which is usually called, 


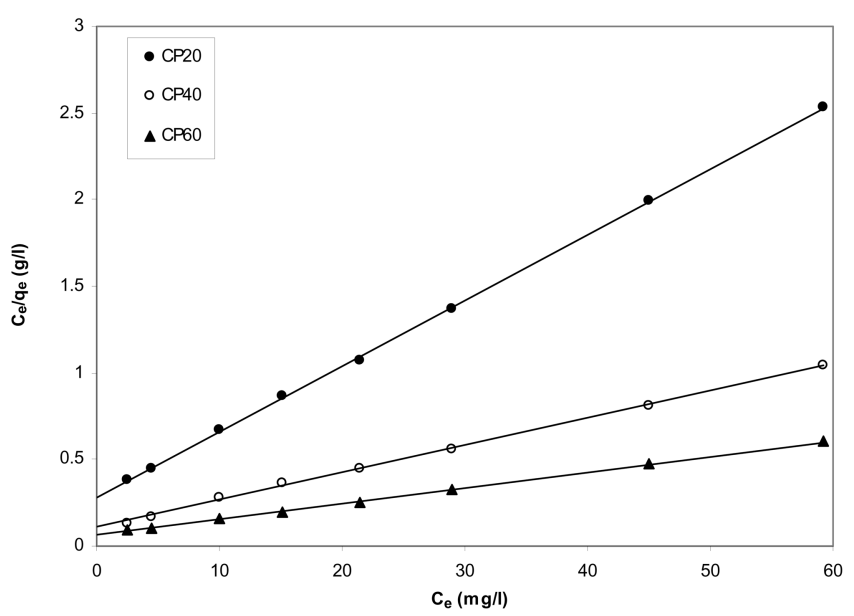

Fig. 9. Linear Langmuir plots for chromium sorption at $30^{\circ} \mathrm{C}$ and $\mathrm{pH} 2.5$ onto CP20, CP40 and CP60.

Table 6. Modeling of Equilibrium Chromium Sorption at $30^{\circ} \mathrm{C}$ and Initial pH 2.5 Onto CP20, CP40 and CP60

\begin{tabular}{crrr}
\hline Sorbent & $\mathrm{q}_{\mathrm{m}}(\mathrm{mg} / \mathrm{g})$ & $\mathrm{b}(1 / \mathrm{mg})$ & $\mathrm{R}^{2}$ \\
\hline CP20 & 29.5 & $11.3 \times 10^{-2}$ & 0.9979 \\
CP40 & 73.9 & $10.8 \times 10^{-2}$ & 0.9991 \\
CP60 & 123.0 & $4.1 \times 10^{-2}$ & 0.9984 \\
\hline
\end{tabular}

the monolayer capacity, and $\mathrm{b}(\mathrm{l} / \mathrm{mg})$ is a constant related to the sorption energy. These sorption parameters were obtained from the linear Langmuir plots shown in Fig. 9. Table 6 gives the $q_{m}$ and $b$ values together with the values of $\mathrm{R}^{2}$ for chromium sorption onto CP20, CP40 and CP60. Fig.9 and Table 6 depict that the equilibrium sorption of chromium fits very well the Langmuir equation. $\mathrm{q}_{\mathrm{m}}$ increases with the increase of the concentration of the phosphoric acid used in carbon activation. The increase of the concentration of phosphoric acid probably increases the surface acidity via creation of carbon-oxygen groups of acidic nature.

Trials have been made to relate the sorption capacity of the carbon sorbents to some of its surface parameters. These trials led to the following observations. (i) chromium sorption increased with the decrease of the surface $\mathrm{pH}$ and $\mathrm{pH}_{\mathrm{PZC}}$ of the carbon sorbent (ii) chromium sorption increased with the increase of surface acidity of the carbon sorbent particularly of the surface acidic group having exchangeable protons such as carboxylics and phenolics.

\section{Conclusions}

Phosphoric acid activated carbons are characterized by high specific surface area and total porosity with these textural parameters increased with the increase of the strength of phosphoric acid used in activation. Phosphoric acid activated carbons are of acidic nature as indicated by their surface $\mathrm{pH}$ and their $\mathrm{pH}_{\mathrm{PZC}}$ being in the acid range.

Removal of $\mathrm{Cr}(\mathrm{VI})$ via sorption onto chemically activated carbons involves reduction to $\mathrm{Cr}$ (III) at solution $\mathrm{pH} 2.5$. Maximum sorption of chromium was always determined from chromium solution at $\mathrm{pH}$ 2.5. Removal of chromium follows first order kinetic at $\mathrm{pH} 2.5$ and second order kinetic beyond this $\mathrm{pH}$. Sorption of chromium is related to the surface $\mathrm{pH}$ of the carbon sorbent and the concentration of the carbon-oxygen groups of acid type on the carbon surface, particularly those having exchangeable protons.

\section{References}

[1] Ajmal, M.; Rifaqat, A. K.; Shahana, A.; Jameel, A.; Rais, A. Bioresearch Technol. 2003, 86, 147.

[2] Romerol, C. B.; Antonio, B.; Gonzo, E. E. Adsorp. Sci. Technol. 2004, 22, 237.

[3] Chen, J. P.; Lin, M. Water Res. 2001, 35, 2385.

[4] Youssef, A. M.; El-Nabarawy, Th.; Samra, S. E.; Colloids and Surfaces A 2004, 235, 153.

[5] Patterson, J. W. "Industrial Wastewater Treatment Technology", $2^{\text {nd }}$ ed., Butterworths Heinemenn, London, 1985.

[6] Raji, C.; Anirudhan, T. S. Water Res. 1998, 32, 3722.

[7] Kobya, M.;.Demirbas, E.; Bayramoglu, M. Adsorp. Sci. Technol. 2004, 22, 583.

[8] El-Hendawy, A. N. A.; Samra, S. E.; Girgis, B. S. Colloids and Surfaces 2001, 180, 209.

[9] Hourieh, M. A.; Alaya, M. N.; Youssef, A. M.; El-Sejarieh, F. Adsorp. Sci. Technol. 1999, 7, 675.

[10] Selomulya, C.; Meeyoo, V.; Amal, R. J. Chem. Technol. Biotechnol. 1999, 74, 111.

[11] Sharma, D. C., Forster, C. F. Bioresource Technol. 1994, 49, 31.

[12] Perez-Candela, M.; Martin-Martinez, J. M.; TerregrasaMacia, R. Water Res. 1995, 29(9), 2174.

[13] Agrawal, G. S.; Bhuptawat, H. K.; Chaudhari, S. Bioresource Technol. 2006, 97(7), 949.

[14] Sharma, D. C.; Forster, C. F. Water SA 1996, 22(2), 153.

[15] El-Shafey, E. I.; Youssef, A. M. Carbon Science 2006, 7(3), 171.

[16] Boehm, H. P. Carbon 1994, 32, 759.

[17] ASTM standard Annual book of ASTM standard "Standard method for $\mathrm{pH}$ of activated carbon", D3838-80, 15.01, 531, 1996.

[18] Haghseresht, F., Nouri, S.; Lu, M. G Q. Carbon 2003, 41, 881.

[19] APHA Standard Methods for the Examination of Water and Wastewater, $16^{\text {th }}$ Ed., American Public Health Association, Washington, D. C., USA, 1985.

[20] Sing, K. S. W.; Everett, D. H.; Haul, R. A. W.; Moscou, L.; Pierotti, R. A.; Rouquerol, J.; Siemieniewska, T. Pure Appl. Chem. 1985, 57, 613.

[21] Brunauer, S.; Emmett, P. H.; Teller, E. J. Am. Chem. Soc. 1938, 60, 309. 
[22] Alaya, M. N.; Youssef, A. M.; Karman, M.; Abdel-Aal, H. E. Carbon Science 2006, 7, 9.

[23] Bansal, R. C.; Donnet, J. B.; Stoeckli, H. F.; "Active Carbon", Marcel Dekker, New York, 1988.

[24] El-Shafey, E. I. Ph. D. thesis, University of Hertfordshire, UK, 2000.

[25] Wittbrodt, P. R.; Palmer, C. D. Enviromn. Sci. Technol. 1995, 29(1), 255.

[26] Ho, Y. S.; Mckay, G Chem. Eng. J. 1998, 70(2), 115.
[27] Gundogan, R.; Acemioglu, B. ; Alam, M. H. J. Colloid and Interface Sci. 2004, 269(2), 303.

[28] Youssef, A. M.; El-Nabarawy, Th.; Samra, S. E. Colloids and Surfaces A 2004, 235, 153.

[29] Raji, C.; Manju, G. N.; Anirudhan, T. S. Water Research 1998, 32, 3062.

[30] Giles, C. H.; MacEwan, T. H.; Nakhwa, S. N.; Smith, D. J. Chem. Soc. 1960, 3973.

[31] Langmuir, I. J. Am. Chem. Soc. 1918, 4, 1361. 